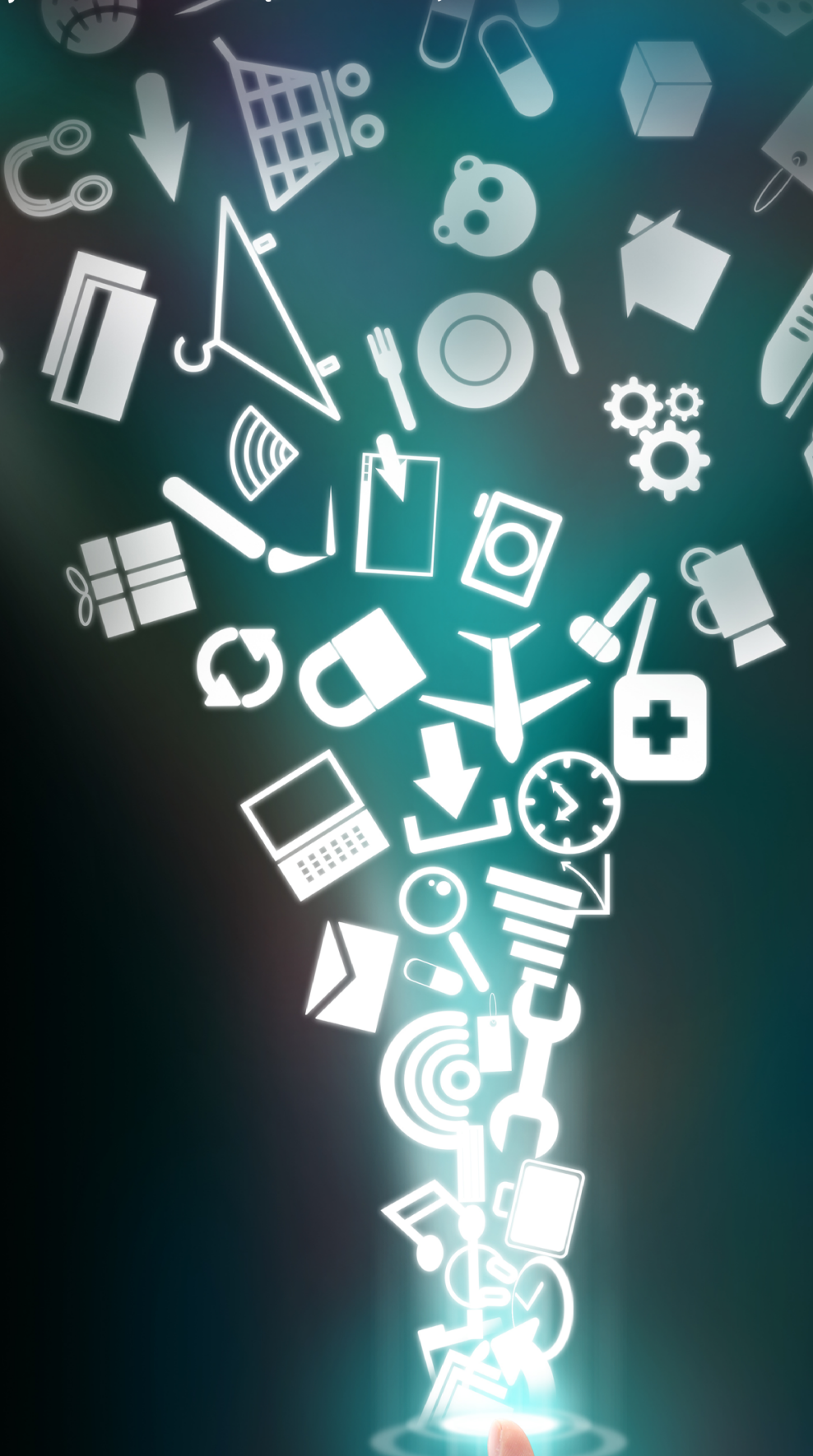




\section{O QUE SERÁ DO VAREJO}

| POR MAURÍCIO MORGADO

Pesquisa mostra que, em três anos, muito vai mudar: a competitividade ficará mais acirrada, a pandemia afetará a sociedade e o mercado de forma duradoura, mudanças na legislação trarão novos desafios, o consumidor exigirá maior coerência e seriedade das marcas e a tecnologia trará muitas novidades, como os superapps e o voice commerce.

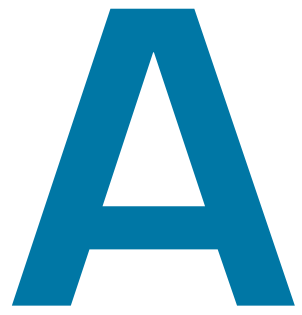

vida dos varejistas nos próximos três anos mudará bastante. A competição ficará mais acirrada, por causa das mudanças provocadas pela pandemia (como o crescimento do home office e das vendas virtuais), das transformações na legislação (Lei Geral de Proteção de Dados Pessoais e open banking), das modificações no comportamento do consumidor (valorização de experiências e hábitos pós-pandemia) e das novas tecnologias (ecossistemas virtuais, superapps, inteligência artificial, big data, voice commerce, realidade virtual e 5G).

Esse é o cenário previsto em um levantamento do Centro de Excelência em Varejo (FGVcev), da Escola de Administração de Empresas de São Paulo, da Fundação Getulio Vargas (FGV EAESP), em conjunto com a Gouvêa Experience. Inicialmente, fizemos um brainstorming com cinco renomados especialistas em varejo, dois do FGVcev e três da Gouvêa Experience. Depois, verificamos a probabilidade de os movimentos detectados acontecerem, na perspecti- va de 91 fundadores, 44 presidentes, 149 diretores, 159 gerentes e supervisores e 44 executivos de outros níveis nas empresas de varejo.

\section{CENÁRIO COMPETITIVO GERAL}

$\mathrm{Na}$ visão dos entrevistados, o mercado estará mais desafiador nos próximos três anos. A competitividade aumentará para $79,1 \%$ deles, enquanto a rentabilidade diminuirá (para 45,2\%) ou ficará igual (para 30\%). A maioria prevê que a concentração de mercado vai crescer $(57,2 \%)$, embora não espere incremento da internacionalização dos negócios varejistas $(37,1 \%$ acreditam em aumento).

$\mathrm{O}$ ambiente econômico traz muitas incertezas. Em todos os cenários econômicos apresentados por meio do brainstorming, o conjunto de entrevistados não apontou firmemente nenhuma tendência. Para eles, há probabilidade média (em torno de $50 \%$ ) de inflação baixa, crédito ao consumidor facilitado, confiança do consumidor reduzida, taxa de juros real próxima de zero e desvalorização cambial no patamar atual, em um cenário político que, acreditam, conti- 


\section{CARACTERÍSTICAS DAS ORGANIZAC̣̃̃ES DIGITALMENTE INTEGRADAS}

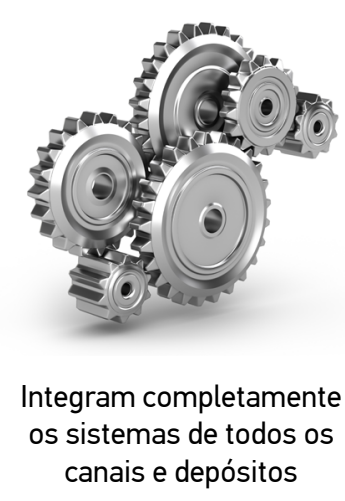

Integram completamente canais e depósitos

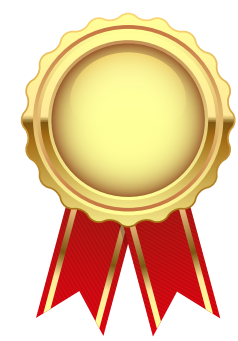

Tratam cada consumidor como único nuará polarizado. Diante de tantas dúvidas, a probabilidade de a renda dos brasileiros aumentar é tida como baixa $(31,9 \%)$ pelos consultados.

Com relação à pandemia, é pequena a chance $(36,6 \%)$ de o setor em que a empresa atua demorar muito para se recuperar, mas os efeitos da Covid-19 devem perdurar e desorganizar estruturalmente alguns ramos do varejo. $\mathrm{O}$ número de consumidores digitais crescerá fortemente $(86 \%$ de probabilidade), e a preocupação com higiene e contaminação veio para ficar $(75,1 \%)$. Por conta da redução do fluxo de pessoas em função do home office e da educação a distância, a vocação comercial de certas áreas da cidade mudará (64\%).

Esperam-se modificações na legislação que permitirão o surgimento do open banking (74,3\% de chance), com movimentação de contas por meio de diferentes plataformas e não só pelo aplicativo ou site do banco, o que pode trazer flexibilização e maior concorrência ao sistema financeiro. Com isso, as fintechs representarão forte concorrência aos bancos tradicionais e serão opção para as empresas oferecerem produtos e serviços ( $69,6 \%$ de probabilidade). Além disso, formas de pagamento instantâneo ficarão mais corriqueiras $(73,2 \%)$, eliminando intermediários da cadeia de provedores financeiros para o varejo. Outra mudança é a Lei Geral de Proteção de Dados Pessoais (LGDP), que exigirá grandes adaptações por parte das empresas (72,3\%), particularmente no que se refere à solicitação de autorizações de uso de dados e cuidados com privacidade e bancos de dados. Já o Cadastro Positivo, legislação também recentemente implantada, tem probabilidade média $(53,9 \%)$ de facilitar o crédito e reduzir os juros.
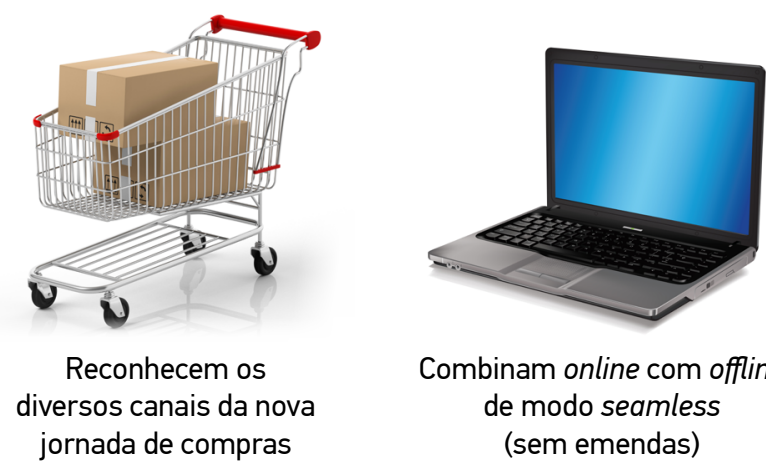

Combinam online com offline de modo seamless (sem emendas)

No que tange a transformações que ocorrerão na sociedade e na cultura, os entrevistados têm bastante convicção das mudanças, pois há probabilidade alta (acima de 65\%) de acontecerem todas as tendências apresentadas pelos resultados do brainstorming. O envelhecimento da população, tendência já apontada há anos, exigirá adaptações significativas nos produtos, na comunicação e nas lojas. Haverá crescimento da preocupação com a privacidade, na esteira do aumento de consumidores digitais. Os consumidores cobrarão cada vez mais responsabilidade social e respeito à diversidade (de gênero, racial, política e social), e a rastreabilidade de produtos será mais valorizada. Também se espera um consumo mais voltado a experiências do que a itens de luxo. Haverá cada vez mais espaço para as marcas serem genuínas e comunicarem um propósito verdadeiro.

\section{O AMBIENTE VAREJISTA E A INFLUÊNCIA DA TECNOLOGIA}

A mais impactante mudança no ambiente varejista provocada pelas novas tecnologias será o fortalecimento dos ecossistemas de negócios (Amazon e Alibaba, por exemplo), com 70,5\% de probabilidade de ocorrer, na visão dos entrevistados. Tais plataformas incluem comercialização online e offline, marketplace, distribuição, pagamento, crédito, serviços e uma infinidade de outros negócios. Considerando as recentes aquisições e movimentações de mercado, o Magazine Luiza parece caminhar na direção de se tornar uma dessas megaplataformas aqui no Brasil.

A distribuição direta pela indústria, com serviços como as lavanderias Omo ou lojas como as da Natura e Granado, tem probabilidade média $(48,4 \%)$ de acontecer. Prati- 


\section{A competitividade do varejo aumentará para $79,1 \%$ dos entrevistados, enquanto a rentabilidade diminuirá ou ficará igual para, respectivamente, 45,2 e 30\% dos executivos consultados.}

camente no mesmo patamar $(47,7 \%)$ estão as chances de as marcas próprias representarem um terço das vendas do varejo - dado que atualmente não respondem por nem $10 \%$ do faturamento.

A tecnologia apresenta-se como uma das grandes alavancas das modificações que o varejo enfrentará nos próximos anos. É esperado forte crescimento das vendas por e-commerce: em média, os entrevistados acreditam que o percentual das vendas virtuais em relação ao total ficará em $35,8 \%$, o quádruplo do patamar atual. Haverá o surgimento dos superapps (66\% de probabilidade), aplicativos pelos quais será possível comprar e pagar todos os tipos de compra, englobando também ferramentas de comunicação e mídias sociais.

As vendas online serão turbinadas pelo maior acesso à banda larga (internet rápida) e pela tecnologia $5 \mathrm{G}$, que propicia transmissão de vídeos de alta resolução na internet - as possibilidades para demonstração remota de produtos crescerão muito. Visualiza-se a popularização do uso de tecnologias de big data (manipulação e cruzamento de dados dos clientes) e de inteligência artificial (modelos computacionais preditivos do comportamento dos clientes), com alta chance de ocorrer ( 68,8 e $66,1 \%$, respectivamente). Realidade virtual (simulação online de produtos, ambientes e pessoas) e voice commerce (compras com comando de voz na Alexa, Siri e Google Assistant) têm probabilidade média de se tornarem comuns (59,7 e 54,6\%, respectivamente). Chances mais baixas $(35,9 \%)$ terão as lojas autônomas, no estilo Amazon Go, que operam sem funcionários.

Todas as mudanças permitem imaginar que a educação e o treinamento online superarão em número de alunos os modelos presenciais de ensino e treinamento, uma verdadeira revolução no setor. Para os entrevistados, esse cenário tem média probabilidade de correr $(52,8 \%)$.

\section{ORGANIZAC̣ÕES}

\section{DIGITALMENTE INTEGRADAS}

Qual é o perfil das organizações varejistas capazes de enfrentar esse futuro projetado por especialistas e gestores? Diante desse universo em transformação, as empresas varejistas precisam se tornar organizações digitalmente inte- gradas (ODIs). Os sistemas das ODIs são interconectados, de forma que é possível saber quantas unidades de produto estão disponíveis em cada canal ou depósito. O consumidor tem acesso a essas informações em todas as interfaces que utilizar.

Cada tíquete de compra é armazenado no histórico do cliente, cupom a cupom, permitindo o uso de inteligência artificial para identificar padrões de consumo e apoiar uma comunicação bem direcionada. Durante o atendimento pessoal, os colaboradores têm acesso a esse histórico e podem fazer recomendações personalizadas, além de estarem o tempo todo conectados entre si por meio de softwares de comunicação e de monitoramento de desempenho. A integração é tão completa que o consumidor se sente único no relacionamento com a marca.

Varejistas ODIs reconhecem a nova jornada de compras e sabem que os consumidores acessam os mais diversos canais durante o processo decisório. Conhecem também o que cada cliente espera de cada canal e são capazes de entregar experiências memoráveis, independentemente da forma de interação com a marca.

A combinação do online com o offline é feita de modo seamless (sem emendas), e o cliente não consegue perceber mudanças de plataformas ou de tratamento, sentindo-se único nesse relacionamento personalizado que a marca lhe oferece.

Construir uma ODI envolve muito mais uma questão de mentalidade, um jeito de pensar sobre o relacionamento que a marca tem com o cliente, do que propriamente a disponibilidade de dinheiro e recursos. O futuro do varejo demandará empresas conectadas, focadas e integradas.

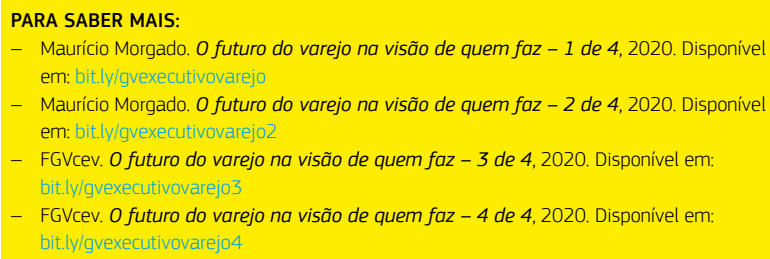

MAURICIO MORGADO > Professor da FGV EAESP e coordenador do Centro de Excelência em Varejo (FGVcev) > mauricio.morgado@fgv.br 